\title{
INFLUÊNCIA DO GENÓTIPO NOS LIPÍDEOS TOTAIS E NA FRAÇÃO INSAPONIFICÁVEL DA CARNE DE CORDEIROS
}

\author{
INFLUENCE OF BREED ON THE LIPID AND \\ UNSAPONIFIABLE FRACTION OF LAMB MEAT
}

\author{
Eiane Mattos Monteiro $^{1}$ Massami Shimokomaki $^{2}$
}

\section{RESUMO}

O objetivo deste trabalho foi comparar o conteúdo de lipídeos totais e componentes da fração insaponificável no Longissimus dorsi de cordeiros de cruzamento absorvente Ile de France $x$ Corriedale ( $F 1)$, em relação à raça Corriedale. Um total de vinte cordeiros machos inteiros foram divididos em dois grupos: cruza IF x C $(n=10)$ e Corriedale $(n=10)$. O manejo alimentar ovelha/cordeiro foi estabelecido em uma área de pastagem natural, melhorada. Os cordeiros foram abatidos com idade média de 150 dias e com pesos médios de 33,08 $( \pm 1,20) \mathrm{kg}$ $e$ de $26,42( \pm 1,37) \mathrm{kg}$, respectivamente. A gordura foi extraída, saponificada, os esteróis foram separados por cromatografia de camada delgada e o colesterol foi quantificado por cromatografia gasosa. Os resultados médios e os desvios padrões obtidos no músculo Longissimus dorsi das cruzas (IF x C) e da raça Corriedale, em g\% foram: lipídeos totais 2,13 $( \pm 0,42)$ e 2,12 ( $\pm 0,41)$; teor de matéria insaponificável 3,28 ( $\pm 0,65)$ e 3,69 ( \pm 0,94); teor de esterol (na matéria insaponificável) 44,05 ( $\pm 7,33)$ e 52,29 $( \pm 7,05)(P<0,01)$; enquanto o teor de colesterol $(\mathrm{mg} / 100 \mathrm{~g}$ base úmida ) foi de $38,37( \pm 4,58)$ e 39,16 $( \pm 7,09)$, respectivamente. $O$ cruzamento IF x C (F1) não resultou em modificações para conteúdo de lipídeos totais e de colesterol, quando comparados com a raça Corriedale.

Palavras-chave: cordeiro, raça, cruzamento, fração lipídica.

\section{SUMMARY}

The objective of this work was to compare total lipids content and composition of the unsaponifiable fraction of the Longissimus dorsi in crossbred Ile de France $x$ Corriedale (IF $x$ C,F1) lambs with Corriedale lambs $(C)$. A total of twenty ram lambs was divided in two groups: crossbred IFxC $(n=10)$ and $C(n=10)$. These were mantained in an improved native pasture and they were slaughtered at the age of 150 days with an average weight of $33.08 \mathrm{~kg}( \pm 1.20)$ and $26.4 \mathrm{~kg}( \pm 1.37)$, respectively. The lipids were extracted from the Longissimus dorsi samples, the saponified and the unsaponifiable (sterols) fractions were analysed by thin chromatography and the cholesterol content ( $\mathrm{mg} / \mathrm{lo0g})$ was performed on a gas chromatography. The results showed averages (in $g \%$ ) of 2.13 $( \pm 0.42)$ and $2.12( \pm 0.41)$ for total lipids; $3.28( \pm 0.65)$ and 3.69 $( \pm 0.94)$ for unsaponifiable fraction; $44.05( \pm 7.33)$ and 52.59 $( \pm 7.05)$ for sterols $(P<0.01)$; whereas the averages for cholesterol ( $\mathrm{mg} / \mathrm{lo0g}$ in wet based) were $38.37( \pm 4.58)$ and 39.16 ( \pm 7.09$)$ for IFxC and C Longissimus dorsi samples, respectively. The IFxC cross (F1 ram lambs) did not result in modification of contents total lipids and cholesterol contents when compared with the Corriedale breed.

Key words: meat lamb, breed, crossbreeding, lipids, cholesterol.

\section{INTRODUÇÃO}

Para atender a atual demanda dos consumidores, quanto ao padrão de qualidade da carne, os estudos vêm se direcionando para o aumento da massa muscular nas carcaças ovinas, com a diminuição do seu teor de gordura (POLLOTT et al., 1994). As pesquisas têm indicado que um largo segmento da população encontra-se consciente da relação alimento $\mathrm{x}$ saúde, $\mathrm{e}$ preocupada quanto ao teor de gordura e colesterol presente na carne (McNAMARA,1990; SOLOMON et al., 1991; CAMERON et al., 1994). Dentre as estratégias utilizadas com esse objetivo, destacam-se a escolha da raça (LEYMASTER \& JENKINS, 1993), da dieta (WEBB et al.,1994), do sexo dos animais (THATCHER et $\boldsymbol{a l}$., 1990) e do uso de

\footnotetext{
${ }^{1}$ Médico Veterinário, Doutor, Pesquisador CPPSUL/EMBRAPA, Caixa Postal 242, 96400-970, Bagé, Rio Grande do Sul. Autor para correspondência.

${ }^{2}$ MS Pesquisador CNPQ-CCA-Universidade Estadual de Londrina, Caixa Postal 6001, 86051-970, Londrina, Paraná.

Recebido para publicação em 07.07.98. Aprovado em 11.11.98
} 
promotores de crescimento (LOUGH et al., 1993). O objetivo deste trabalho foi comparar a fração lipídica do músculo Longissimus dorsi de cordeiros resultantes de cruzamento absorvente Ile de France $\mathrm{x}$ Corriedale (F1) em relação à raça Corrriedale.

\section{MATERIAL E MÉTODOS}

O presente trabalho utilizou vinte cordeiros, machos inteiros, 10 resultantes de cruzamento absorvente (F1) (ovelha Corriedale $\mathrm{x}$ carneiro Ile de France) e 10 da raça Corriedale (ovelha Corriedale x carneiro Corriedale). O manejo alimentar ovelha/cordeiro foi estabelecido em uma área de pastagem natural, melhorada com gramíneas Cynodon dactylon cv. Coastcross, Chloris gayana $\mathrm{e}$ Brachiaria humidicola. Os cordeiros foram abatidos com idade média de 150 dias e com pesos médios ao abate de $33,08( \pm 1,20) \mathrm{kg}$ as cruzas e de 26,42 $( \pm 1,37) \mathrm{kg}$ a raça Corriedale. As amostras para as análises da fração lipídica foram coletadas no músculo Longissimus dorsi, em toda sua extensão (porções - craneal, intermediária e caudal) e sem gordura subcutânea.

Para a extração e determinação dos lipídeos totais, foram utilizados, de cada carcaça, em torno de 200g do músculo Longissimus dorsi livre do gordura externa. As extrações dos lipídeos totais foram realizadas, levando-se em consideração as proporções recomendadas nos solventes metanol, clorofórmio e água, antes e depois da diluição $1: 2: 0,8$ e $2: 2: 1,8$, respectivamente, de acordo com o método BLIGH \& DYER (1959). O teor de gordura do extrato foi determinado gravimetricamente. A sequência das análises, encontra-se na figura 1.

Alíquotas do extrato lipídico foram saponificadas com uma mistura de álcool absoluto e $\mathrm{KOH}$ aquosa a $50 \%$, em aquecimento com refluxo por uma hora. $\mathrm{O}$ material foi submetido a diferentes lavagens: as três primeiras foram realizadas com água e éter etílico, seguidas de mais três lavagens com solução de $\mathrm{KOH} 0,5 \mathrm{~N}$ e água, e as últimas três, apenas com água, até tornar-se neutro à fenolftaleína. A solução etérea, contendo o insaponificável, foi transferida para um balão volumétrico tarado, evaporado em rotaevaporador e levado à estufa, até peso constante. A partir desse material, foi realizada a cromatografia preparativa de camada delgada. Utilizaram-se placas de sílica gel de $0,5 \mathrm{~mm}$ de espessura, empregando-se como eluente a mistura hexano:éter etílico (1:1). Após a eluição, as placas foram reveladas com fluoresceína em câmara de ultravioleta. A fração esterólica assim obtida foi marcada e raspada, e os esteróis, extraídos por éter etílico, foram quantificados gravimetricamente.

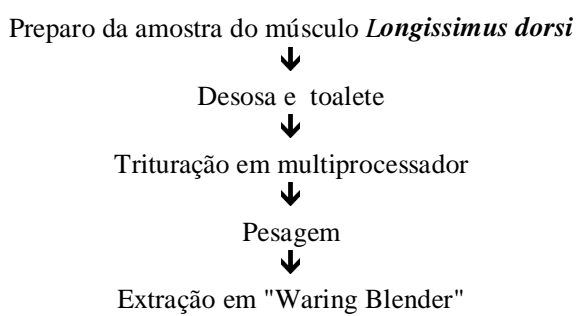

Preparo da amostra do músculo Longissimus dorsi $\downarrow$ Desosa e toalete $\downarrow$

Trituração em multiprocessador $\downarrow$

Pesagem

$\boldsymbol{\downarrow}$

Extração em "Waring Blender"

extração inicial clorofórmio e metanol 2:1 / 2 minutos

2 extrações com clorofórmio e metanol 1:1/30 segundos cada

Filtração do material em funil de Büchner e separação da fase etérea por decantação $\downarrow$

Fase etérea balão volumétrico tarado evaporação do solvente em rota evaporador $45^{\circ} \mathrm{C} / 15$ minutos $\downarrow$

Secagem em estufa $105^{\circ} \mathrm{C} / 30$ minutos $\downarrow$ Pesagem da gordura $\downarrow$ Saponificação $\downarrow$

Extração do insaponificável $\downarrow$

Cromatografia preparativa $\downarrow$

Cromatografia gasosa

Figura 1 - Fluxograma da análise.

A determinação do colesterol foi realizada por cromatografia gasosa de alta resolução em cromatógrafo a gás HP-5890, série II, equipado com detector de ionização de chama. Foi empregada coluna Capilar $12 \mathrm{~m}$ de sílica fundida de HP1 (SE$30), 12 \mathrm{M} \mathrm{X} 0,20 \mathrm{MM} \times 0,33 \mu \mathrm{M}$. A temperatura da coluna foi de $260^{\circ} \mathrm{C}$, do injetor $280^{\circ} \mathrm{C}$ e do detector $300^{\circ} \mathrm{C}$. A identificação do colesterol foi realizada pela comparação do tempo de retenção dos picos da amostra com o dos padrões analisados nas mesmas condições, e a quantificação do colesterol foi realizada através do integrador-processador HP-3996. A separação dos insaponificáveis, do esterol e a quantificação do colesterol foram realizadas conforme AMERICAN OIL CHEMIST'SOCIETY (1989). Os resultados foram submetidos a análises estatísticas, através de cálculos de média, desvio padrão, sendo aplicado teste "T-Student" para verificar o nível de significância entre as médias CURI, (1997).

\section{RESULTADOS E DISCUSSÃO}

Os teores de lipídeos totais, de matéria insaponificável, esterol e de colesterol no músculo Longissimus encontram-se na tabela 1. No teor de 
Tabela 1 - Médias, desvio padrão e variância dos componentes da fração lipídica no Longissimus dorsi nos dois grupos.

\begin{tabular}{lccc}
\hline Variáveis & Corriedale & Cruza (IF x C) & Significância \\
\hline & & & \\
gordura $(\mathrm{g} \%)$ & $2,12( \pm 0,41)$ & $2,13( \pm 0,42)$ & $\mathrm{ns}$ \\
matéria insap $(\mathrm{g} \%)$ & $3,69( \pm 0,94)$ & $3,28( \pm 0,65)$ & $\mathrm{ns}$ \\
esterol $(\mathrm{g} \%)$ & $52,29( \pm 7,05)$ & $44,05( \pm 7,33)$ & $*$ \\
colesterol $(\mathrm{mg} / 100 \mathrm{~g}$ amostra) & $39,16( \pm 7,09)$ & $38,37( \pm 4,58)$ & $\mathrm{ns}$ \\
& & & \\
\hline
\end{tabular}

Ns: não significativo;

* Diferem sionificativamente $\mathrm{P}<0.01$

esterol, observou-se superioridade da raça Corriedale em relação às cruzas $(\mathrm{P}<0,01)$. Já, para os lipídeos totais, matéria insaponificável e colesterol, no músculo Longissimus dorsi dos cordeiros, a raça Corriedale e as cruzas Ile de France x Corriedale não diferiram estatisticamente. Entretanto, diferenças raciais e valores superiores para o teor de lipídeos em músculos do quarto (perna) foram descritos por MONTEIRO et al. (1995), ao avaliarem cordeiros de cinco genótipos, castrados, manejados em pastagem cultivada e abatidos aos 120 dias de idade, que não diferiram entre si. Para as raças Corriedale e Romney Marsh, os valores foram de 4,02 e 4,00g\%, com diferença significativa em relação às cruzas Texel $\mathrm{x}$ Corriedale e às raças Ideal e Merino $(\mathrm{P}<0,05)$, cujos valores variaram entre 3,75 e $3,63 \mathrm{~g} \%$ e não diferiram. SOLOMON et al. (1980), ao compararem o Longissimus de cordeiros cruzas $1 / 2$ Suffolk x $1 / 4$ Finnish Landrace x 1/4 Southdown ( $\mathrm{Su}$ x F x So) e Suffolk x Rambouillet (Su x R), também encontraram diferenças significativas $(\mathrm{P}<0,01)$ para a percentagem de lipídeos, as cruzas Su x F x So apresentaram maior teor de lipídeos do que a $\mathrm{Su} x \mathrm{R}$. Com o mesmo objetivo, LEYMASTER \& JENKINS (1993) demonstraram que os valores para o teor de lipídeos foram significativamente relacionados com a raça $(P>0,01)$, sendo que a raça Texel apresentou $7 \%$ menos gordura inter/intramuscular do que a raça Suffolk. DRANSFIELD et al. (1990) também observaram diferenças ao compararem o Longissimus de cordeiros, resultantes do cruzamento de ovelhas $1 / 2$ Blueface Leicester e $1 / 2$ Blackface com carneiros Dorset Down e Suffolk. As cruzas Suffolk apresentaram menor teor de lipídeos totais, quando comparadas com as cruzas Dorset Down.

Os valores para o teor de colesterol (tabela 1), encontrados nos cordeiros Corriedale e cruzas (IF x C), ficaram abaixo dos $66,60 \mathrm{mg} / 100 \mathrm{~g}$ encontrados por SOLOMON et al. (1990) no músculo Longissimus de cruzas Suffolk x Hampshire Down, criados em regime de confinamento. Teores elevados para o colesterol foram encontrados por
ABU-TARBOUSH \& DAWOOD (1993), ao avaliarem a gordura subcutânea nos cortes paleta, lombo, costela e perna de ovinos das raças Nadji e Merino. Os valores para o corte paleta, nas duas raças, foram de 199 e $209 \mathrm{mg}$ de colesterol/100g de gordura, enquanto nos demais cortes, os resultados foram inferiores aos da paleta e apresentaram variação de 182 a $193 \mathrm{mg}$ de colesterol/100g de gordura nas duas raças avaliadas.

Os valores médios para o teor de colesterol, no presente trabalho, foram inferiores aos acima citados e alguns fatores podem ser associados a estas diferenças como: manejo alimentar, quantidade de gordura subcutânea e intramuscular, idade, raça e a própria metodologia utilizada para determinação do colesterol. Entretanto, os resultados dos cordeiros foram comparáveis aos de BRAGAGNOLO (1997), no músculo Longissimus de bovino das raças Nelore, Canchin e Beefalo. Os valores médios encontrados, expressos em $\mathrm{mg} / 100 \mathrm{~g}$ em base úmida foram de : 40,00 Nelore e Beefale e de 43,00 Canchin, também não foram observadas diferenças significativas ao nível de 0,5 para o teor de colesterol entre as raças. WHEELER et al. (1987), ao compararem o teor de colesterol no Longissimus das raças Chianina e cruza Hereford $\mathrm{x}$ Angus, não observaram diferenças entre as raças (P>0,05), os valores médios foram de 62,71 e de $63,92 \mathrm{mg} / 100 \mathrm{~g}$ de colesterol, respectivamente.

\section{CONCLUSÕES}

O cruzamento absorvente Ile de France $\mathrm{x}$ Corriedale (F1) não influencia os teores de lipídeos totais, matéria insaponificável e colesterol do Longissimus dorsi dos cordeiros quando comparados a raça Corriedale. Entretanto, considerando a relevância do tema no momento atual, mais estudos devem ser conduzidos com um número maior de amostras e, inclusive, com avaliação e uniformização das análises do colesterol na carne.

\section{AGRADECIMENTOS}

Os autores agradecem aos pesquisadores, técnicos e laboratoristas do Setor de Óleos e Gorduras CTAA/EMBRAPA, pela valiosa colaboração na execução deste trabalho.

\section{REFERÊNCIAS BIBLIOGRÁFICAS}

ABU-TARBOUSH, H.M., DAWOOD, A.A. Cholesterol and fat contents of animal adipose tissues. Food Chemistry, v. 46, p. 89-93, 1993. 
AMERICAN OIL CHEMISTS'SOCIETY. Analyses of fats, oils and lipoproteins. . Urbana, Illinois: Edward G. Perkins, 1989. $664 \mathrm{p}$.

BLIGH, E.G., DYER, W.J. A rapid method of total lipid extraction and purification. Canadian Journal Biochemical Physiology, v. 37, p. 911-917, 1959.

BRAGAGNOLO, N. Fatores que influenciam o nível de colesterol, lipídeos totais e composição de ácidos graxos em camarão e carne. Campinas, SP.123p. Tese (Doutorado em Ciência dos Alimentos) - Curso de Pós-graduação em Engenharia de Alimentos, Universidade Estadual de Campinas, 1997.

CAMERON, N.D., BISHOP, S.C., SPEAKE, B.K., et al. Lipid composition and metabolism of subcutaneous fat in sheep divergently selected for carcass lean content. Animal Production, v. 58, p. 237-242, 1994.

CURI, P.R. Metodologia e análise da pesquisa em ciências biológicas. Botucatu, 1997. $263 \mathrm{p}$

DRANSFIELD, E., NUTE, G.R., HOGG, B.W., et al. Carcass and eating quality of ram, castrated ram and ewe lambs. Animal Production, v. 50, v. 2, p. 291-299, 1990.

LEYMASTER, K.A., JENKINS, T.G. Comparison of Texel and Suffolk sired crossbred lambs for survival, growth and compositional traits. Journal Animal Science, v. 71, n. 4, p. 859-869, 1993

LOUGH, D.S., KAHL, S., SOLOMON, M.B., et al. The effects of trenbolone on performance, plasma lipids an characteristics of growing ram and ewe lambs. Journal Animal Science, v. 71, p. 2659-2665, 1993.

McNAMARA, D.J. Relation between blood and dietary cholesterol. In : PEARSON, A.M., DUTSON, T.R. Meat and health - Advances in meat research. London, England: Elsevier Applied Science, 1990. v. 6, Cap. 3, p. 63-87.
MONTEIRO, E., VAZ, C., BORBA, M., et al. Composição física de cinco raças ovinas. In: SIMPÓSIO LATINO AMERICANO DE CIÊNCIAS DOS ALIMENTOS,1995, Campinas, SP, Anais..., Campinas: Universidade Estadual de Campinas, 1995. v. 1, p. 86.

POLLOTT, G.E., GUY, D.R., CROSTON, D. Genetic parameters of lamb carcass characteristics at three end-points: fat level, age and weight. Animal Production, v. 58, p. 65-75, 1994.

SOLOMON, M.B., KEMP, J.D., MOODY, W.G., et al. Effect of breed and slaughter weight on physical, chemical and organoleptic properties of lamb carcasses. Journal Animal Science., v. 51, n. 5, p. 1102-1107, 1980.

SOLOMON, M.B., LYNCH, G.P., ONO, K., et al. Lipid composition of muscle and adipose tissue from crossbred ram, wether and cryptorchid lambs. Journal Animal Science, v. 68 , p. $137-142,1990$.

SOLOMON, M.B., LYNCH,G.P., PAROCZAY, E., et al. Influence of rapeseed meal, whole rapeseed, and soybean meal on fatty acid composition and cholesterol content of muscle and adipose tissue from ram lambs. Journal Animal Science, v. 69 , p. $4055-4061,1991$

THATCHER, L.P., MADEN, J.J.L., PLANT, C.L. Influence of sex and year on carcass characteristics important in the marketing of second cross lambs. Australian Journal of Experimental Agriculture, v. 30, p. 171-177, 1990.

WHEELER, T.L., DAVIS., G.W., STOECKER, B.J., et al. Cholesterol concentration of Longissimus muscle, subcutaneous fat and serum of two beef cattle breed types. Journal Animal Science., v. 65, p. 1531-1537, 1987.

WEBB, E.C., CASEY, N.H., VAN NIERKERK, W.A. Faty acids in the subcutanous tissue of intensively fed SA Mutton Merino and Dorper wethers. Meat Science, v. 13, 123-131, 1994.

Ciência Rural, v. 29, n. 3, 1999. 